\title{
60 Years in 100 Days: How COVID-19 Exposes the Lethality of Social Inequality
}

\author{
Gabriella Emilly Pessoa, Laboratory of Geoiconography and Multimedia, Department \\ of Geography, University of Brasília,Brazil, gabriellaemilly@gmail.com \\ Valdir Adilson Steinke, Laboratory of Geoiconography and Multimedia, Department of \\ Geography, University of Brasília, Brazil, valdirsteinke@gmail.com
}

\begin{abstract}
The pandemic outbreak of COVID-19 had begun in March of 2020 on a global scale. This outbreak has originated numerous questions for society and many challenges for public managers. The disease is worrying because it has a high propagation velocity, high lethality levels, and there is no cure. Some groups are considered more vulnerable due to pre-existing disease conditions, age-range, and living conditions. In Latin American countries, people live in different conditions than those who live in countries located in the North hemisphere, such as climatic conditions, less favorable socioeconomic conditions, different educational levels, inequality, precarious urban infrastructure, etc. These factors generate even more concern and uncertainty about the pandemic than in developed countries. This study aimed, although preliminarily, to identify areas of great socio-spatial vulnerability and susceptibility of infection of people over 60 years old of COVID-19 in Brasília, Brazil. In this research, publicly available data and information about the population characteristics and social aspects were used, all connected directly to the census sectors. With the support of Geographic Information System (GIS), a matrix was used to cross-check the data and, thereby, achieve the objective of identifying the most vulnerable sectors for people aged over 60 years old. The results point out to more than 400 census sectors classified as Extremely Vulnerable in Brasília and it should be the object of special attention for public managers to do specific health care actions.
\end{abstract}

Keywords: coronavirus; urban socio-spatial vulnerability; health inequity; pandemic outbreak.

\section{Background}

The Coronavirus (COVID-19) was discovered in Wuhan, Hubei Province of China after several people were reported with pneumonia in late December of 2019. Some of them had direct contact with a seafood market located there $[1,2]$.

Now, the virus has spread throughout the world causing several deaths and collapsing healthcare systems around the globe, mostly because of human-to-human transmission. $20 \%$ to $30 \%$ of the infected patients required mechanical ventilation and $10 \%$ died, with higher fatality rates in elderly patients and those with medical comorbidities such as diabetes, hypertension, cancer, renal and lung diseases, and coinfections [3, 4].

As stated by [5] on August $10^{\text {th }}$ of 2020, the world had at least $19,718,030$ confirmed cases and 728,013 confirmed deaths in more than 200 countries, proving this disease is very contagious.

Symptoms of this disease include cases of fever, cough, myalgia, fatigue, chest discomfort, sputum production, headaches, hemoptysis, and diarrhea [2,6]. Until August $10^{\text {th }}, 2020$, there were no vaccines available for the COVID-19 or other pharmaceutical treatment. The best way to prevent the disease is to intervein with non- 
pharmaceutical ways, such as suppression and mitigation interventions made by the governments of numerous countries.

All technologies developed by humanity can be used in hospitals and clinics to establish a highly interconnected digital world that can be used to deep learning systems to understand healthcare trends, model risk associations, and predict future outbreaks. Therefore, healthcare systems should use digital technology to mitigate COVID-19's impact. [7]

Geographic Information Systems (GIS) can be used to identify the spatial and temporal distribution of diseases and its agents, its causes, and to evaluate the probability of epidemics. Also, combining it with other kinds of software, allows it to predict and model the diseases over time and space. GIS software along with scientific methods can be a helpful tool for the surveillance and control of disease vectors in general, helping to formulate management policies and actions. Next-generation sequencing and bioinformatics can help us to improve our response to infectious disease outbreaks, our understanding of disease occurrence and transmission, occasioning the process of identification of pathogens, and promoting data sharing [2, 8, 9]

The spatial analysis in a medical context has three principal objectives: first, to identify disease clusters; second, to explain the spatial distribution of the clusters; and third, to predict the risk of disease. Mapping allows visualization of any existing spatial patterns and it helps to elaborate hypothesis for further analysis. To do correct analysis, it is important to not only know the distribution but also the concentration of disease agents (both human and animal), the migration of people around the world, and the migration of disease agents among species - due to a globally connected world [9].

The world cannot ignore health equity to contain the epidemic. Health disparities/inequality is the difference in which disadvantaged social groups experience worse health or greater health risks than wealthy, powerful, or prestigious groups. It is important to reach out to the most marginalized and vulnerable people to contain the spread of the pandemic disease COVID-19. As healthcare systems collapse around the world because it cannot keep up with the infected number of patients confirmed with coronavirus, vulnerable people diagnosed with COVID-19 cannot be hospitalized. Under-resourced people who live in urban clusters are more likely to die during this global pandemic. Those disparities could be eliminated with health equity $[10,11]$.

There are two forms of non-pharmaceutical interventions (NPIs) to reduce the mortality of COVID-19. The first one is called suppression: the aim is to decrease the average number of secondary cases each new case generates. As long as the virus circulates, the cities will maintain this intervention until a vaccine is available. The second one is called mitigation and its objective is to not interrupt the virus's transmission completely, allowing the population to increase immunity. This one has an eventual fast decline in case reports and the human-to-human transmissions reach low levels. It is suggested that wide social distancing combined with intermittent mitigation and suppression would have the largest impact on mortality levels and transmissions [12].

By the Brazilian Constitution of 1988, the Federal District has the same function as a city. Therefore, it is not a municipality. The Federal District is synonymy for Brasília, the capital of the Federative Republic of Brazil and it is composed of 33 Administrative Regions (Figure 1), which can also be called cities. 


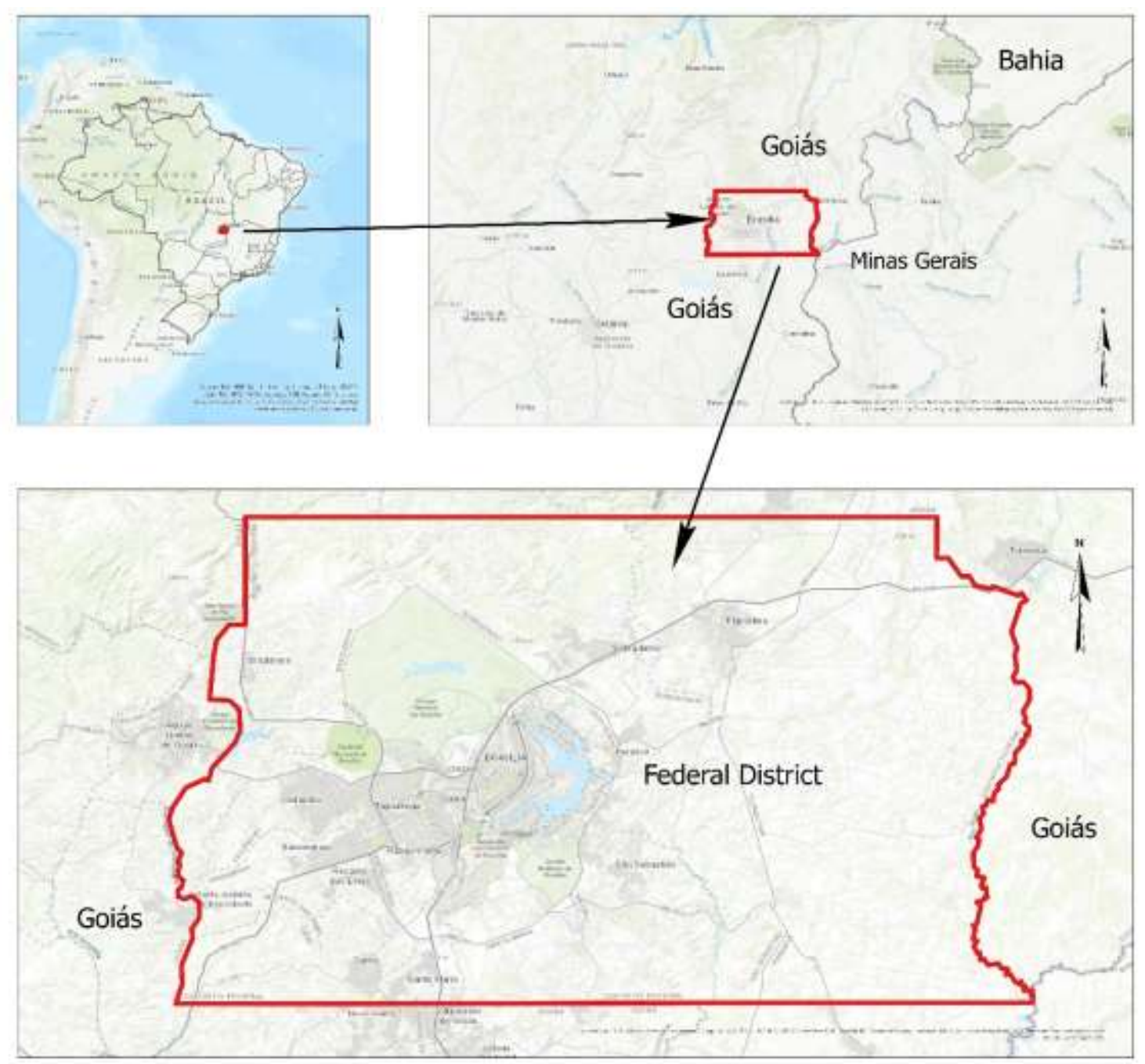

Figure 1. Map of the location of the capital of Brazil, Brasília, Federal District.

The major incidence of COVID-19 on June 14 of 2020, is in the Central part of the Federal District (Plano Piloto, Sudoeste/Octogonal, Cruzeiro, Lago Norte, Lago Sul, and Varjão do Torto), which includes the richest neighborhoods of Brasília. However, the highest lethality rates are located at the West, Southeast, South-Center, and North parts of the capital, which includes the poorest neighborhoods of the city, such as Estrutural and Ceilândia [13].

COVID-19 was confirmed on February 25th in Brazil and, twenty days later, Brasília confirmed its first case. Brasília, on June $14^{\text {th }}, 2020$, reported 22,871 confirmed cases of COVID-19: $61 \%$ are recovered and 1.3\% deceased. The capital reported 304 deaths until that date, with a fatality rate of $1.3 \%$ [13].

Brasília has 205 hospital beds dedicated to COVID-19 intensive care. 185 of the hospital beds reserved for the intensive treatment of COVID-19 are from the public healthcare system (175 reserved for adults and 10 reserved for children). The rest of them are from the private healthcare system, with no pediatric hospital beds for the treatment of COVID-19 [14].

Even though Brasília has fewer cases than cities like São Paulo and Rio de Janeiro until now, it has a higher risk of infection than the two last cited cities. In the next weeks, Brasília could surpass São Paulo in the number of cases. The predictions 
indicate that both private and public healthcare systems will not endure the number of positive cases for COVID-19 and, eventually, it will collapse [15].

Gradually, the Government of Brasília started to implement actions to decrease the spread of the virus. On March 3rd, 2020, the governor suspended all classes in schools and universities and, two days later, he decided to suspend non-essential local stores.

The predictions show that if there were no mitigation measure, the number of the cases in the Federal Districts would duplicate every three days; with the actual mitigation measures (canceling all classes and closing all non-essential local stores), the cases will duplicate every 5 days; and, with measures of suppression or total social isolation, the cases will duplicate every 10 days. By April 21st, 2020, Brasília would have 493,568 confirmed cases, therefore, this would be the disease's peak at the Capital: 98,714 could need hospitalization and between 14,807 and 14,678 could need ICU hospital beds. In this scenario, the deaths could accumulate between 3,949 and 16,781 [15].

In Brazil, the virus was imported from the wealthy classes who were visiting countries in Europe, such as Italy - the former epicenter of COVID-19. The first cases reported in Brasília were from the inhabitants of Lago Sul, one of the richest neighborhoods in the region. COVID-19 rapidly spread to all cities located in the Capital.

The present study focuses on how COVID-19 affects the vulnerable and disadvantaged social groups in Brasília, the city with the greater social inequality indexes among other cities in the country [16].

The main objective is to identify the census sectors of major socio-spatial vulnerability, which can affect directly the spread of the virus infection due to health disparities. This is the first important approach to understand and intervein on the Brasília healthcare system, contributing to Health Geography studies around the globe, since its methodological procedures can be applied in most cities of the world.

\section{Methods}

To achieve the objectives of this article, the first step performed was to collect data and information about Brasília. It was selected the territorial limits; the census sectors; the location of available health units; the routes of the public transportation system; the location of schools; among other information that could assist in the integrated observation of the population dynamics and their eventual exposure to contamination. Figure 2 summarizes the analysis concept of the data and information used and its potential result. 


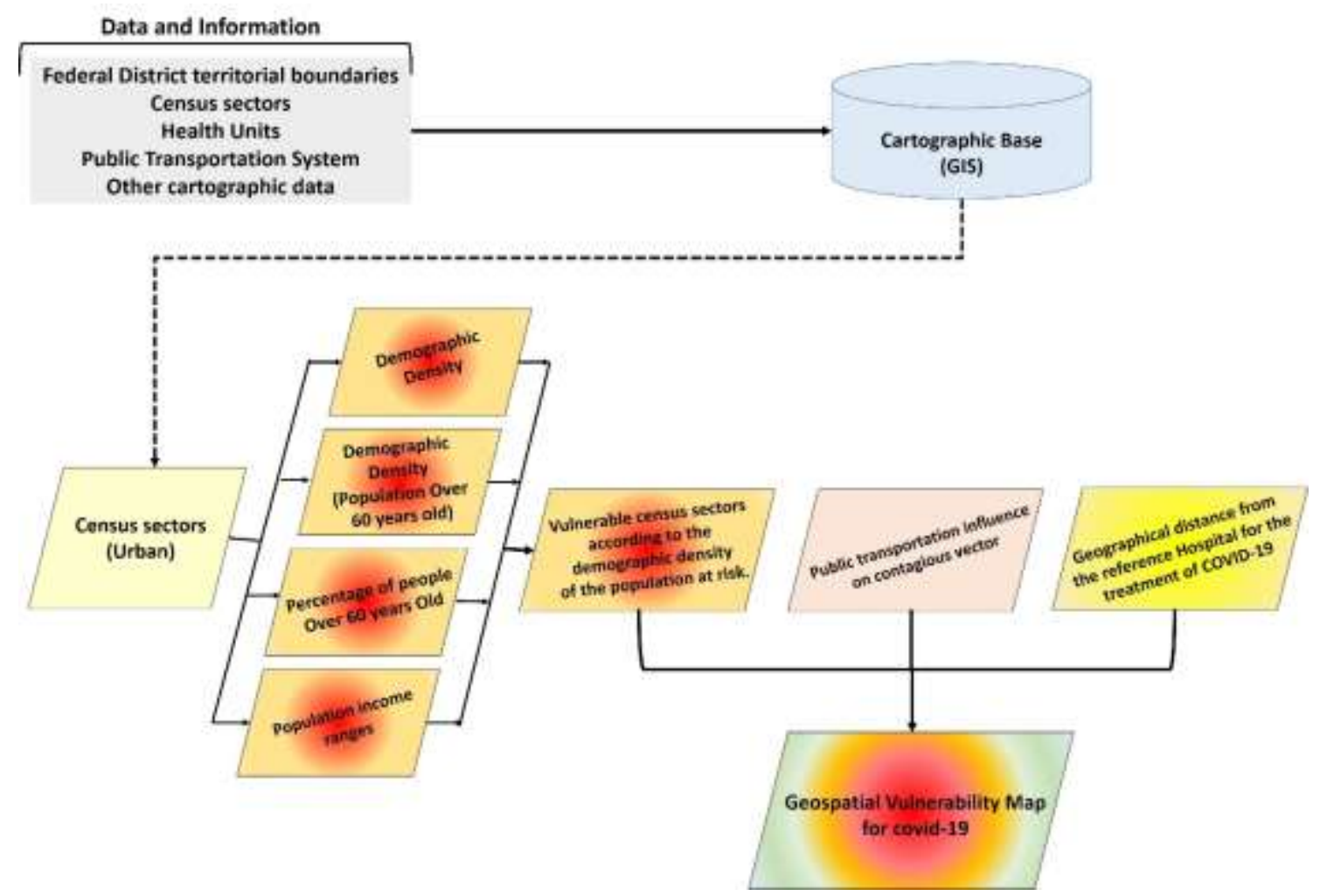

Figure 2. The material and methods flow.

After that, it was important to create a whole cartographic base with the collected data using GIS. This is an important step so it is possible to spatialize the obtained information and understand how the virus can affect the cities of Brasília.

The spatialization of the data will probably lead to the urban census sectors that are potentially more vulnerable to the spread of COVID-19, which are areas where there are major clusters of residences. The spatialized data were: the demographic density; the population over 60 years old, which leads to the percentage of people over 60 years old; and, finally, the population income range. All variables used were classified in a ranking of nine categories. The table below indicates the criteria utilized to define the categories:

\begin{tabular}{lccccc}
\hline & $\begin{array}{c}\text { Demographic } \\
\text { density (hab/ha) }\end{array}$ & $\begin{array}{c}\text { Density 60 years } \\
\text { old (hab/ha) }\end{array}$ & $\begin{array}{c}\text { Habitants above } \\
60 \text { years old }(\%)\end{array}$ & $\begin{array}{c}\text { Geographical distance from } \\
\text { the reference Hospital for the } \\
\text { treatment for COVID-19 }(\mathrm{km})\end{array}$ & Gini coefficient \\
\hline Extremely Low & \multicolumn{1}{c}{} & & & & \\
Very Low & $41-85$ & $8-16$ & $9,1-13$ & 5 & $<0.38$ \\
Low & $85,1-131$ & $16,1-25$ & $13,1-16$ & 10 & $0.381-0.400$ \\
Medium Low & $131,1-184$ & $25,1-36$ & $16,1-19$ & 20 & $0.410-0.430$ \\
Average & $184,1-272$ & $36,1-52$ & $19,1-23$ & 25 & $0.431-0.450$ \\
Medium High & $272,1-434$ & $52,1-78$ & $23,1-28$ & 30 & $0.451-0.460$ \\
High & $434,1-713$ & $78,1-134$ & $28,1-35$ & 35 & $0.461-0.470$ \\
Very High & $713,1-1155$ & $134,1-234$ & $35,1-50$ & 40 & $0.471-0.480$ \\
Extremely High & $>1155$ & $>234$ & $>50$ & 50 & $0.481-0.510$ \\
\hline
\end{tabular}

Table 1. Correlations used between population at risk and socio-spatial vulnerability.

It is important to highlight that for this study the spatial delimitation of the census sectors as defined by the Brazilian Institute of Geography and Statistics 
(Instituto Brasileiro de Geografia e Estatística - IBGE, in Portuguese) and it was used as an analysis cell. Thus, the census sectors are cuts in the territory that shows the real socio-spatial dynamics in urban environments, since it is an analysis cell defined as the "individual level". This approach is useful because the population is currently at different levels of vulnerability in this research.

\section{Results}

The third figure shows the rural and urban census sectors, based on the IBGE census sectors map. It clearly shows a high demographic density in Brasília: there are only 292 rural census sectors and 4205 urban census sectors, even though the rural area occupies a major space of the Federal District.

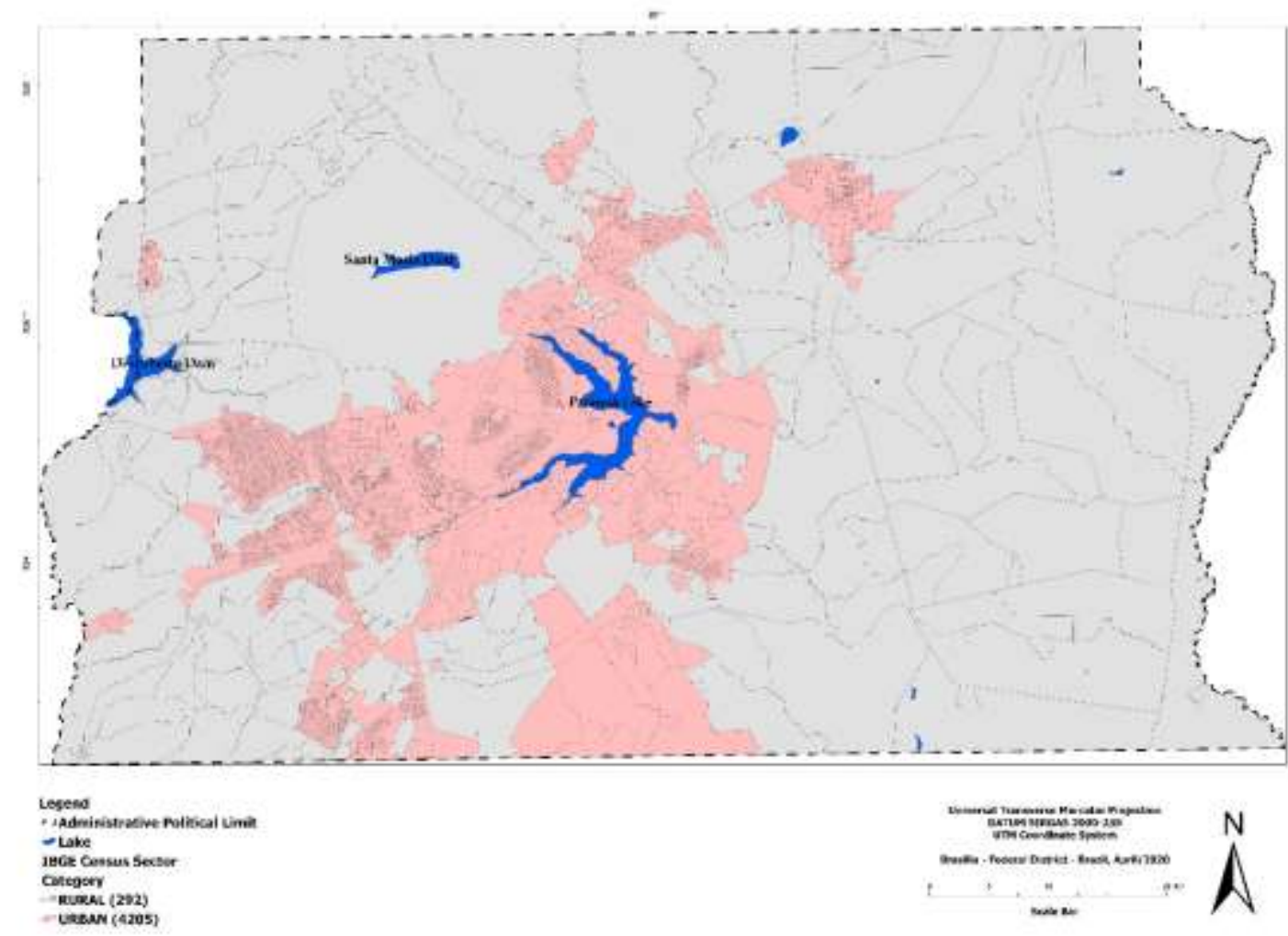

Figure 3. IBGE rural and urban census sector of the Federal District.

Based on the census sector map, it was selected the urban census sectors to understand how dense the urban demography of Brasília is. The range of the demographic density goes from the extremely low to the extremely high. The census sectors located in the range from a high to an extremely high demographic density are the ones that are more vulnerable to the infection of COVID-19 because it shows that there are a lot of people occupying the same space. 


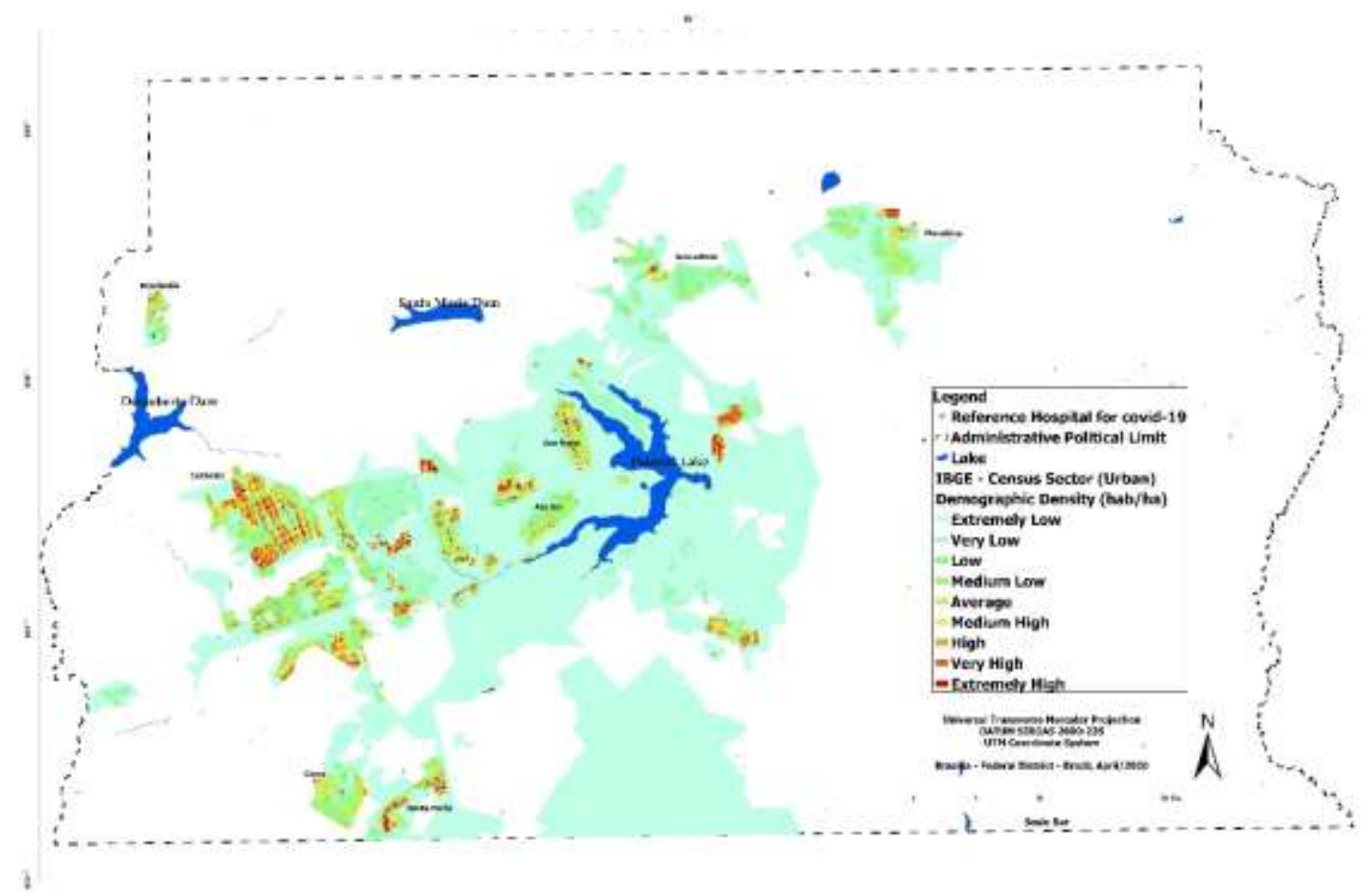

Figure 4. Map of the urban demographic density of Brasília.

The fifth figure shows the demographic density of the population over 60 years old - both parameters indicating the population at a higher risk of contamination. The range of the demographic density of the population over 60 years old goes in the same direction of the last presented map: from the extremely low to the extremely high. People over 60 years old who lives in locations that are in the range from high to extremely high are the ones that are more exposed to the contamination of COVID-19.

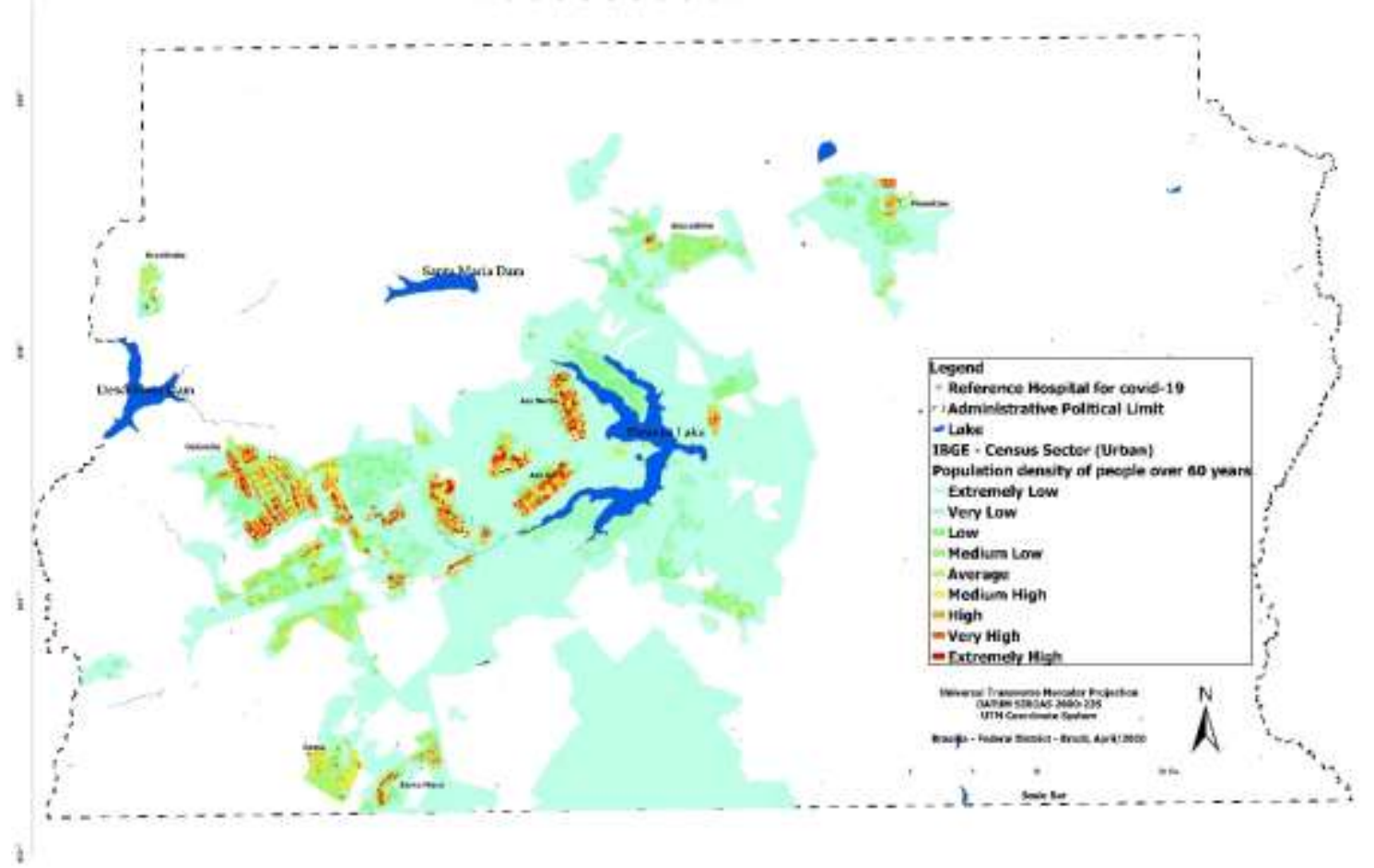

Figure 5. Map of the demographic density of people over 60 years old. 
The next map shows the percentage of people over 60 years old who live in the Federal District. People over 60 years old are one of the groups at risk of COVID-19. Therefore, areas with a higher percentage of people over 60 years old are also the areas more vulnerable to the infection of coronavirus. This information along with the previously cited spatialized data shows the areas with a higher risk of contamination.

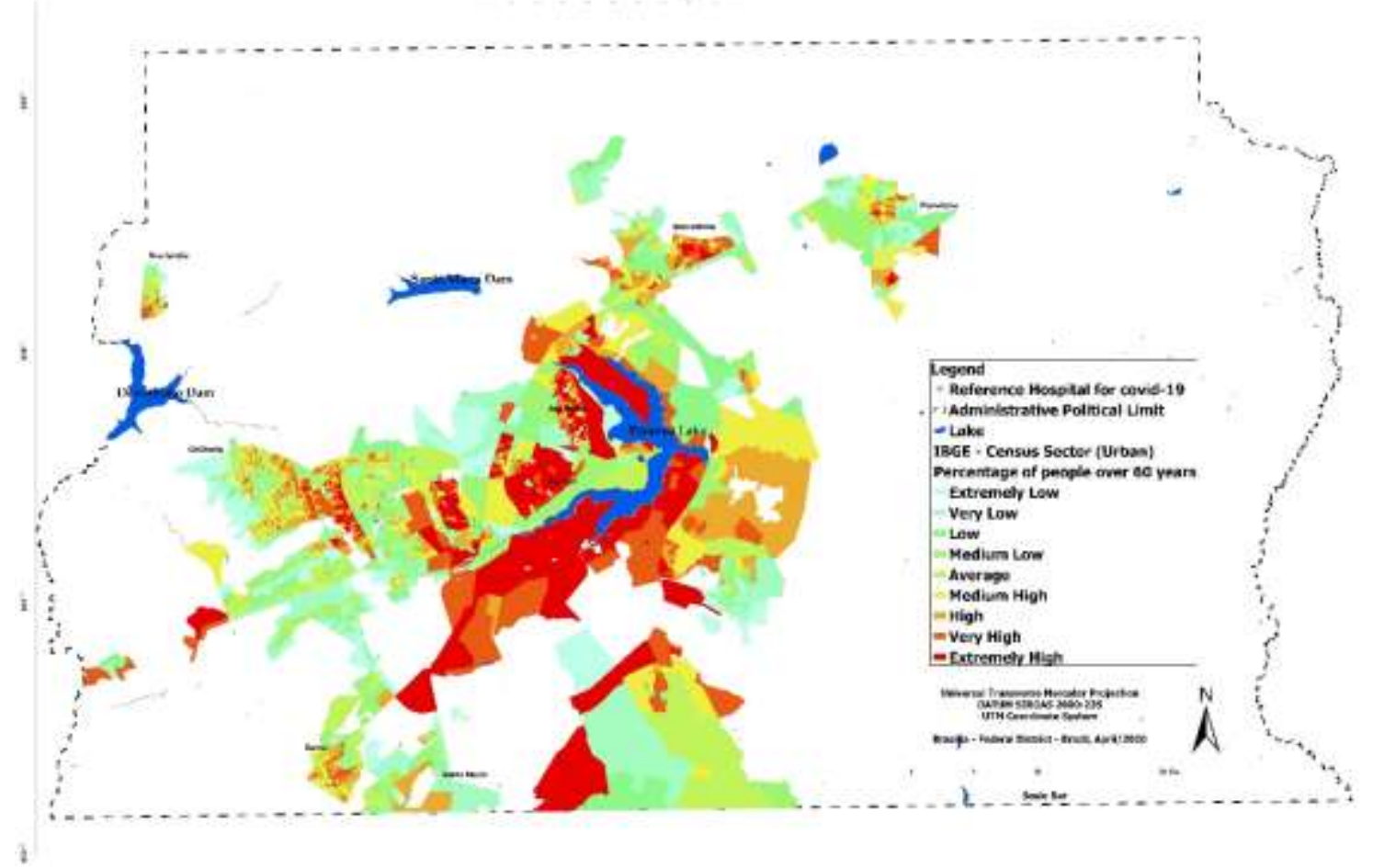

Figure 6. Map of the percentage of people over 60 years old.

The next figure shows the geographical distance of the hospital of reference for the treatment of COVID-19 and the routes that the public transportation system has. The geo-spatial vulnerability increases every $5 \mathrm{~km}$ away from the hospital. These data were crossed with the percentage of people over 60 years old, resulting in the following map: 


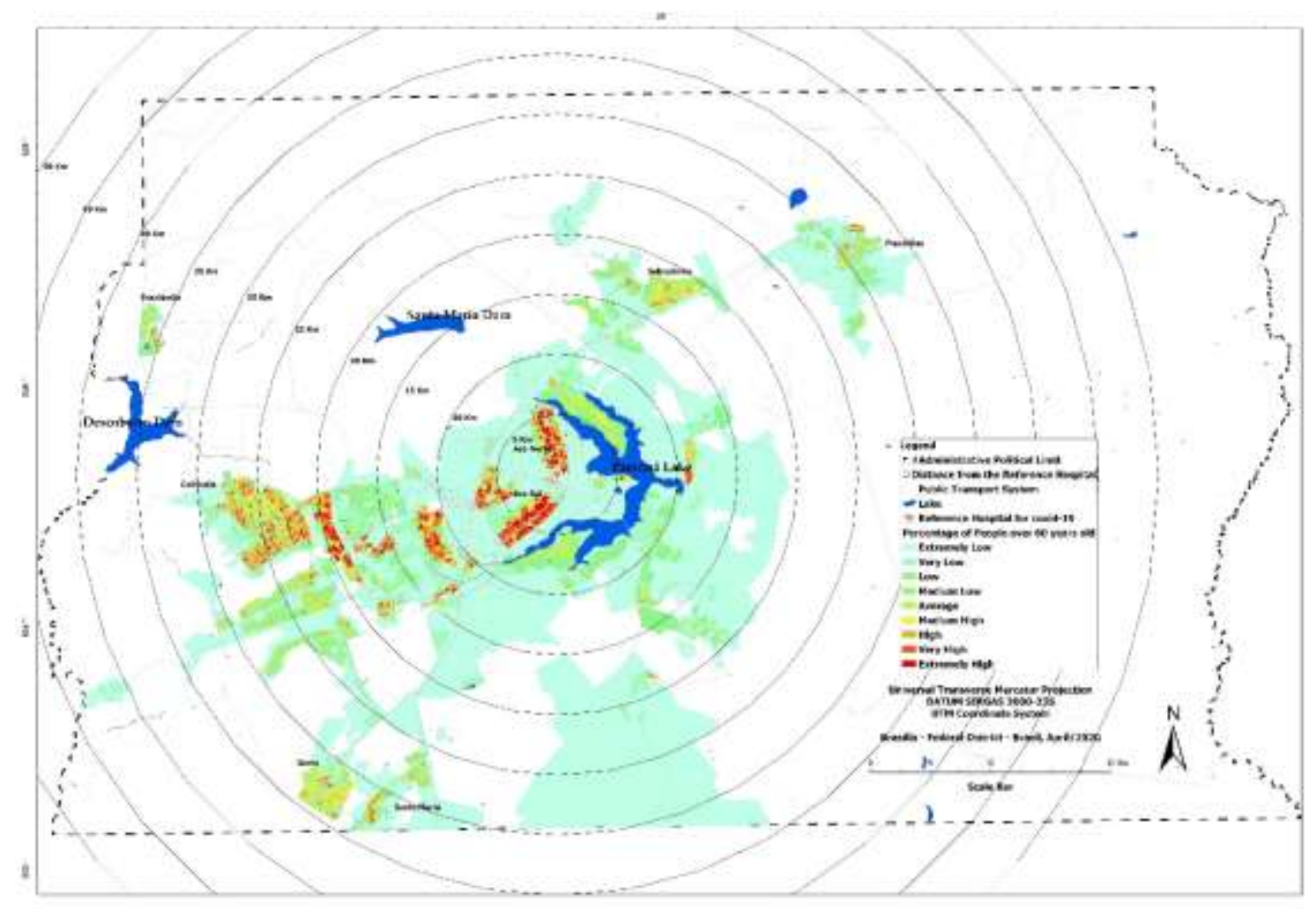

Figure 7. Map of the geographical distance of the Hospital of reference for the treatment of COVID-19.

\section{Discussion}

The final maps (Figure 8 and 9) shows the COVID-19 socio-geospatial vulnerability according to the crossed data of the hospital of reference for the treatment of the virus, the census sectors, the population over 60 years old and the demographic density. 


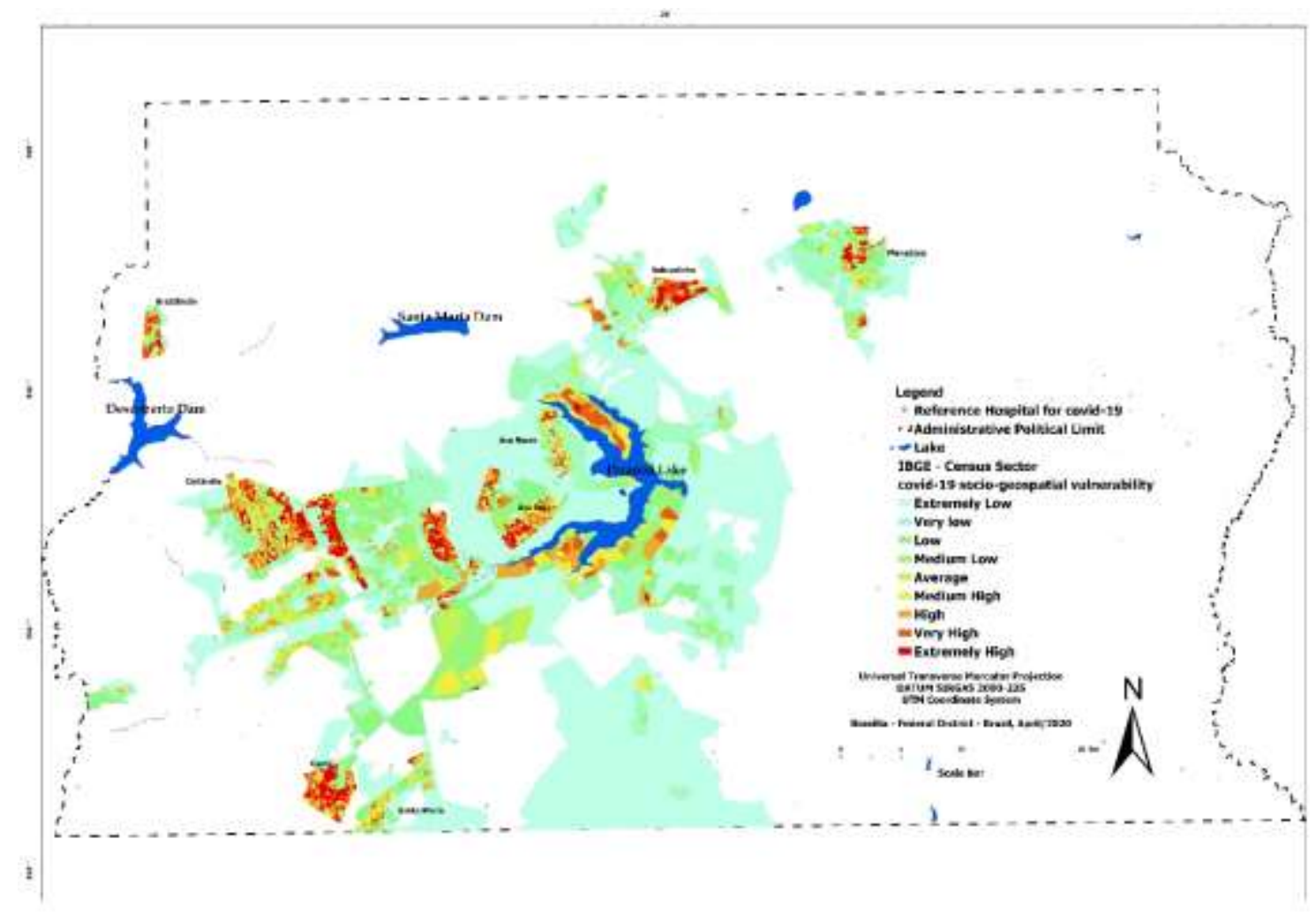

Figure 8. Map of social-spatial vulnerability for the infection of COVID-19.
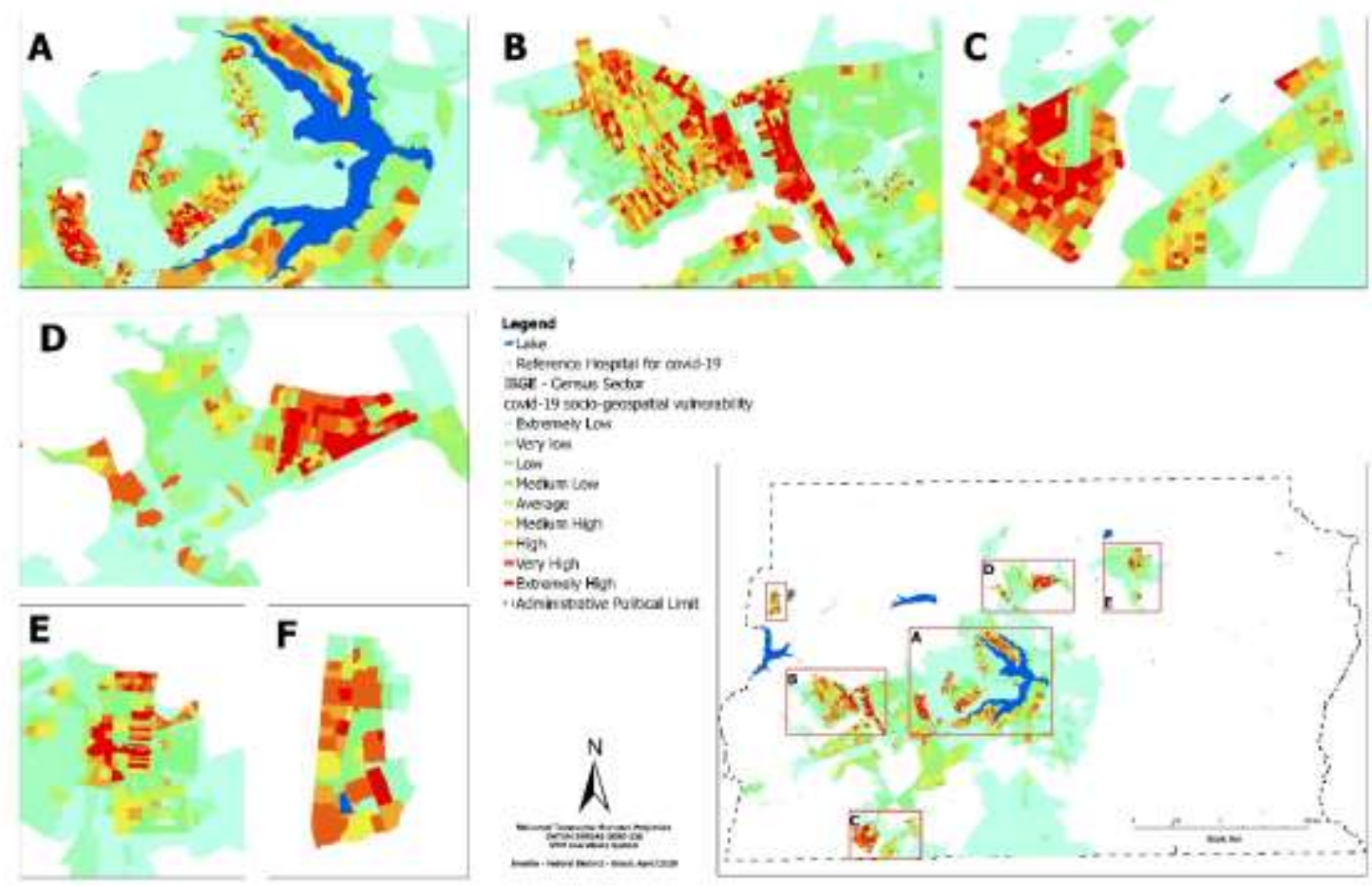

Figure 9. An enlarged version of the social-spatial vulnerability of the COVID-19 map.

The dispersion diagram of Moran bivariate (Figure 10) shows, in the abscissa axis the value of a patterned variable being observed in a determined area, along with the value of another patterned variable being observed in the surrounding area in the ordinate axis. The positive autocorrelation is reinforced when the inclination of the 
regression axis is increased, and the unities tend to group in the first and third quadrant. In contrast, when there is negative spatial autocorrelation, the axis is decreasing and the unities tend to group, in its vast majority, in the second and the fourth quadrant [17].
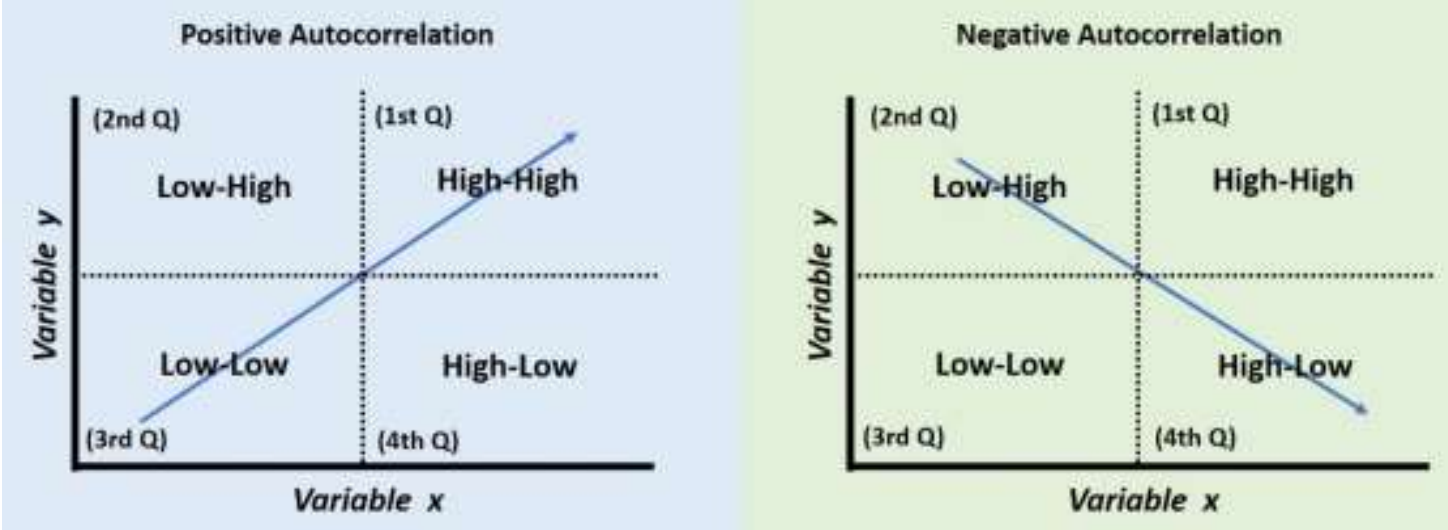

Figure 10. The dispersion diagram of Moran bivariate.

In the first quadrant, there is the grouping of High-High $(\mathrm{HH})$. In other words, the spatial unities which belong to this grouping exhibit areas with a high value of the variable of interest plotted in the abscise axis, having surrounding areas that also present high values in the other variable of interest, which is plotted in the ordinate axis.

The Low-High (LH) grouping represents a whichever spatial unity with a low value of the variable of interest. However, it is surrounded by spatial unities with a high value of another variable. This situation is represented in the second quadrant.

The Low-Low (LL) grouping refers to the spatial unities where it is observed low values of the variable of interest. This grouping is surrounded by spatial unities that also have low values in the other variable, represented by the third quadrant.

The High-Low (HL) grouping involves a cluster that has a whichever spatial unity with a high value in the variable of interest. This grouping is surrounded by spatial unities with low value, being in the fourth quadrant.

According to [17], it is possible to obtain a local spatial multivariate autocorrelation measure. It is supposed that there are two variables of interest, $\mathrm{Z}_{1}$, and $\mathrm{Z}_{2}$. The sixth equation represents the I of Moran bivariate local:

$$
I_{i}^{Z_{1} Z_{2}}=Z_{1 i} W Z_{2 i}
$$

Where: $Z_{1}$ is a variable of interest and $W Z_{2 i}$ is the spatial gap of the other variable of interest $W Z_{2 i}$ in the surrounding area.

Therefore, only the surroundings of the observation $i$, defined by a matrix of spatial values, are included in the calculus. The local indicator of spatial association (LISA) provides the level of a statically significant spatial autocorrelation in each regional unity [18]. In the same way that occurs in the univariate analysis, combining the information of the bivariate Moran diagram with the LISA map of significance, it is possible to obtain the cluster map with bivariate regimes that allows a more adequate 
geographical visualization of the concentration level of the studied variables $[19,20$, 21].

The data analysis shows that the general demographic density and its significance to the spatial correlation are slightly negative.

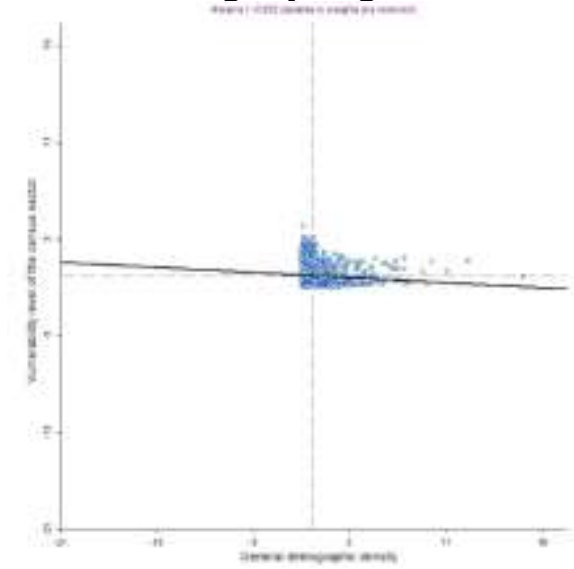

Figure 11. The general demographic density where the spatial correlation is slightly negative.

When the sample of the demographic density of the people with age equal or superior to 60 years old is analyzed in a bivariate spatial correlation, this behavior roughly changes, and it starts to show a positive spatial autocorrelation.

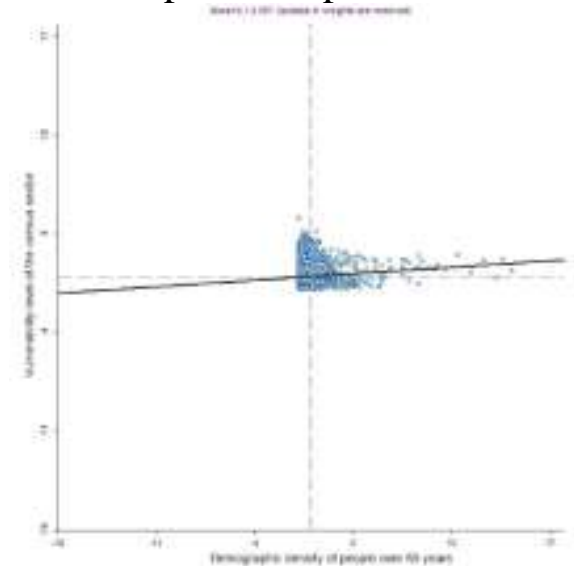

Figure 12. The demographic density of people with 60 or more years old in a spatially correlated bivariate has a positive spatial autocorrelation.

However, when it is autocorrelated in the same type of analysis, the data which refers to the percentage of people with age equal or superior to 60 years old by census sector and its relevance in the final result, the graphic significantly changes and leaves evident the positive autocorrelation. 


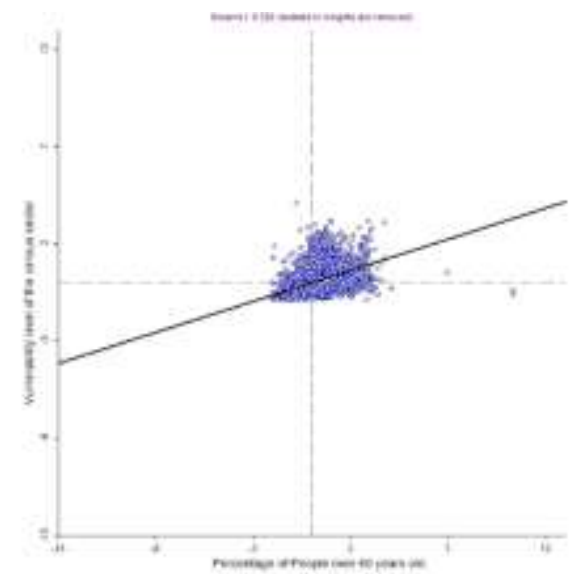

Figure 13. When there is an autocorrelation between people with the age of 60 years old or superior to that by the census sector, the autocorrelation is positive.

This was a definitive factor in identifying the census sector with the highest socio-spatial vulnerability because, in general, only the demographic density has been used as criteria, which in some scenarios is sufficient. However, the general demographic density associated with the percentage of people over 60 years old is a variable that increases the capacity to identify the sectors of highest vulnerability.

The results point out the vulnerability of people over 60 years old, which according to the data presented so far are the ones who most demand hospital services and, especially, Intensive Care Units.

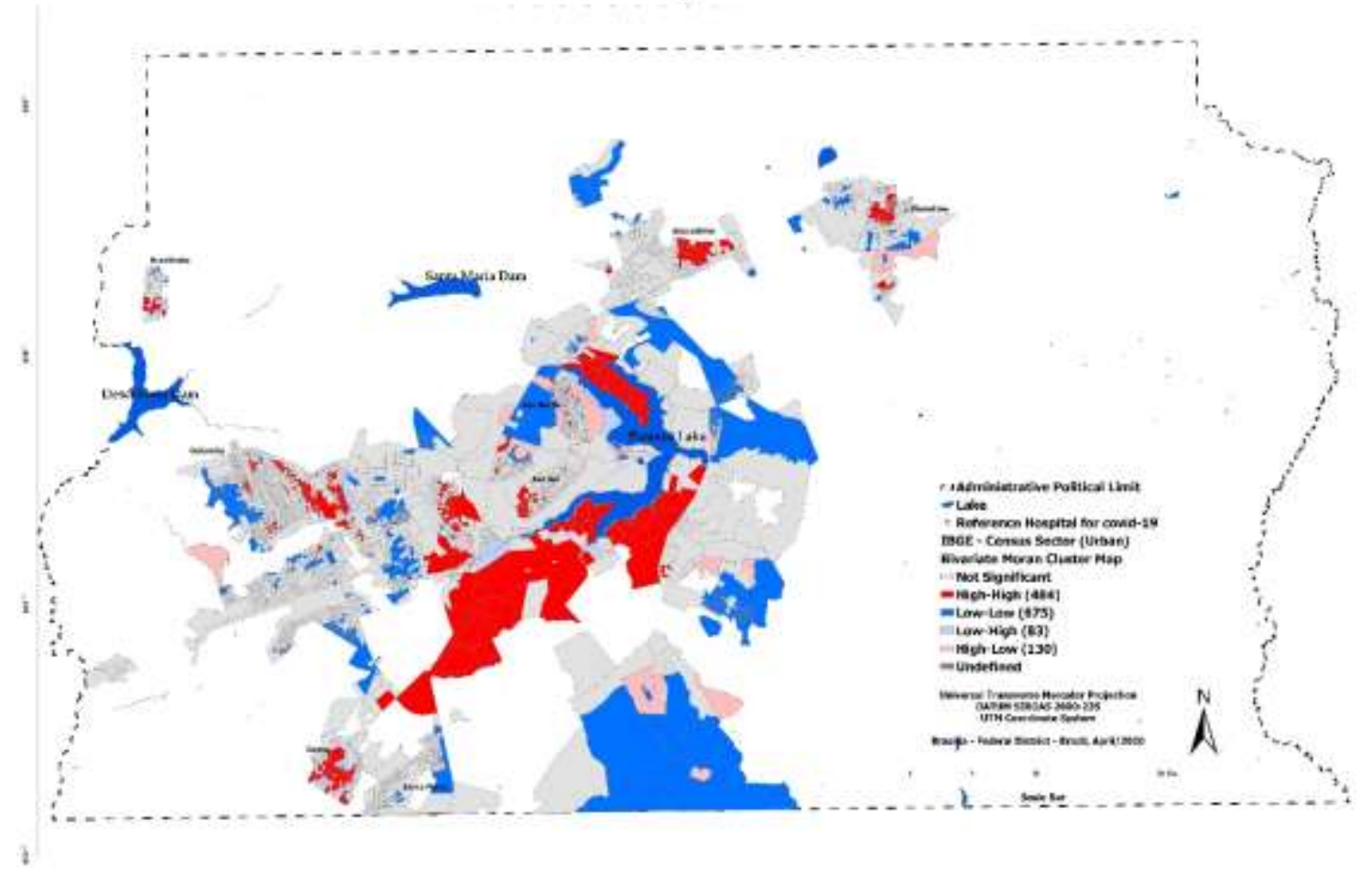

Figure 14. The Bivariate Moran Cluster Map points out the most vulnerable cities.

Figure 14 shows a correlation spatial map, indicating that Brasília has 484 sectors of $\mathrm{HH}$ correlation and 675 of LL correlation, totalizing 1,141 sectors of direct correlation pointed in the map by the colors red and blue, respectively. All of those sectors should be monitored since they are at a major risk of contamination and vulnerability, especially for those aged over 60 years old. 
Figure 15 shows another important result to indicate areas of geospatial vulnerability. In this case, the spots show the most vulnerable urban agglomerations in the Federal District. This presentation model offers the possibility to observe spatial agglomerations and their respective interactions with each other. For potential public policies to promote social isolation, this map can be a useful tool since it indicates the areas that can be isolated from the others with a greater degree of effectiveness.

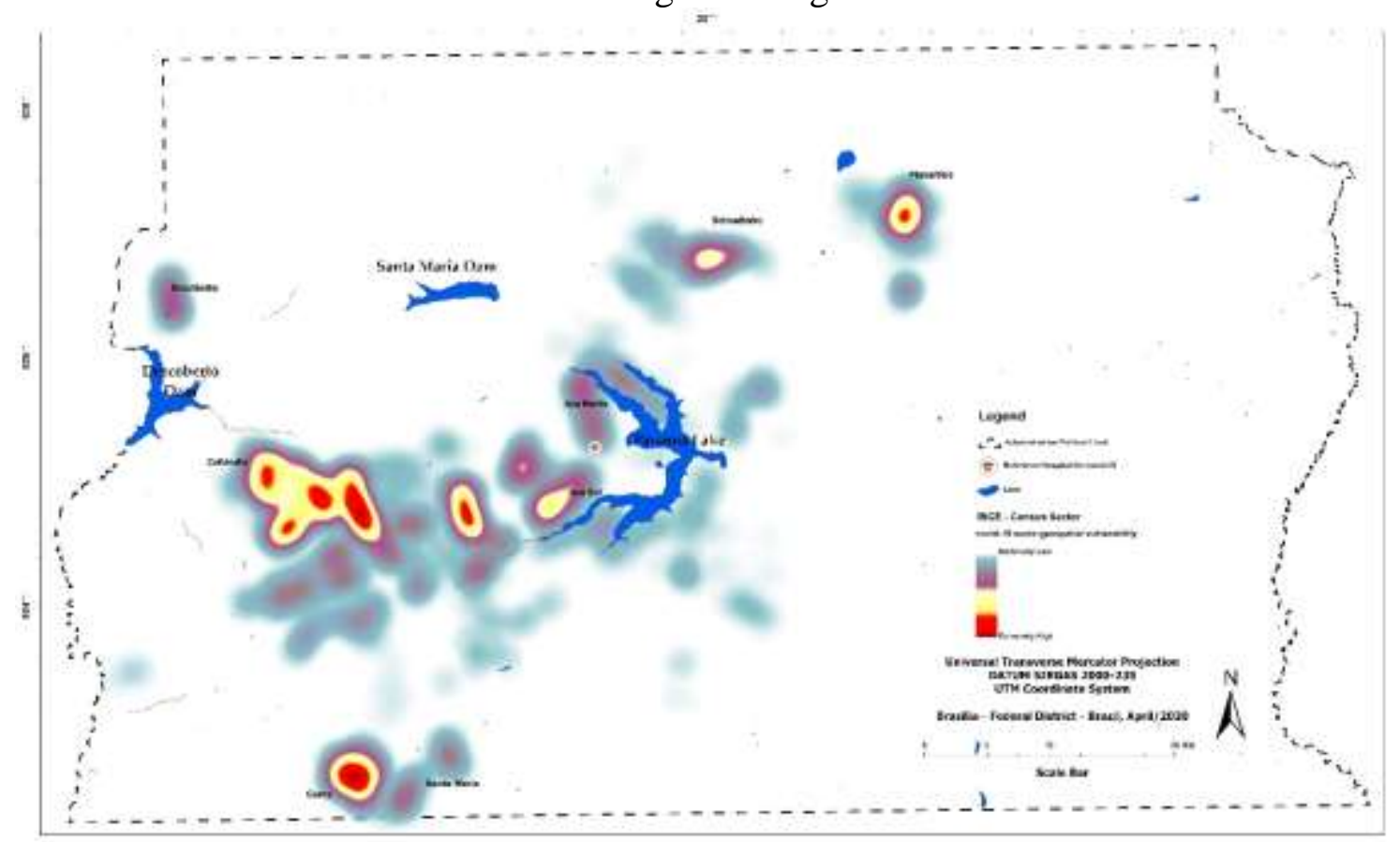

Figure 15. Spatial distribution of the most vulnerable urban agglomerations.

Considering that the socio-spatial vulnerability maps presented in this research were constructed at the beginning of the pandemic in the capital, questions emerged in the following moments of the pandemic. The most important one was: so, how valid these vulnerability maps are? To try to answer this question, it was decided to observe the official daily data of confirmed cases by administrative region.

Coronavirus cases were mapped daily. However, for illustration, table 2 resulted in six maps:

\begin{tabular}{ccc}
\hline Period & Grouping date & Map \\
\hline 03-05-2020 to 03-31-2020 & $03-31-2020$ & Figure 16 \\
04-01-2020 to 04-15-2020 & $04-15-2020$ & Figure 17 \\
04-16-2020 to 04-30-2020 & $04-30-2020$ & Figure 18 \\
05-01-2020 to 05-15-2020 & $05-15-2020$ & Figure 19 \\
05-16-2020 to 05-31-2020 & $05-31-2020$ & Figure 20 \\
06-01-2020 to 06-10-2020 & $06-10-2020$ & Figure 21 \\
\hline
\end{tabular}

Table 2: Grouped daily data for confirmed coronavirus cases 


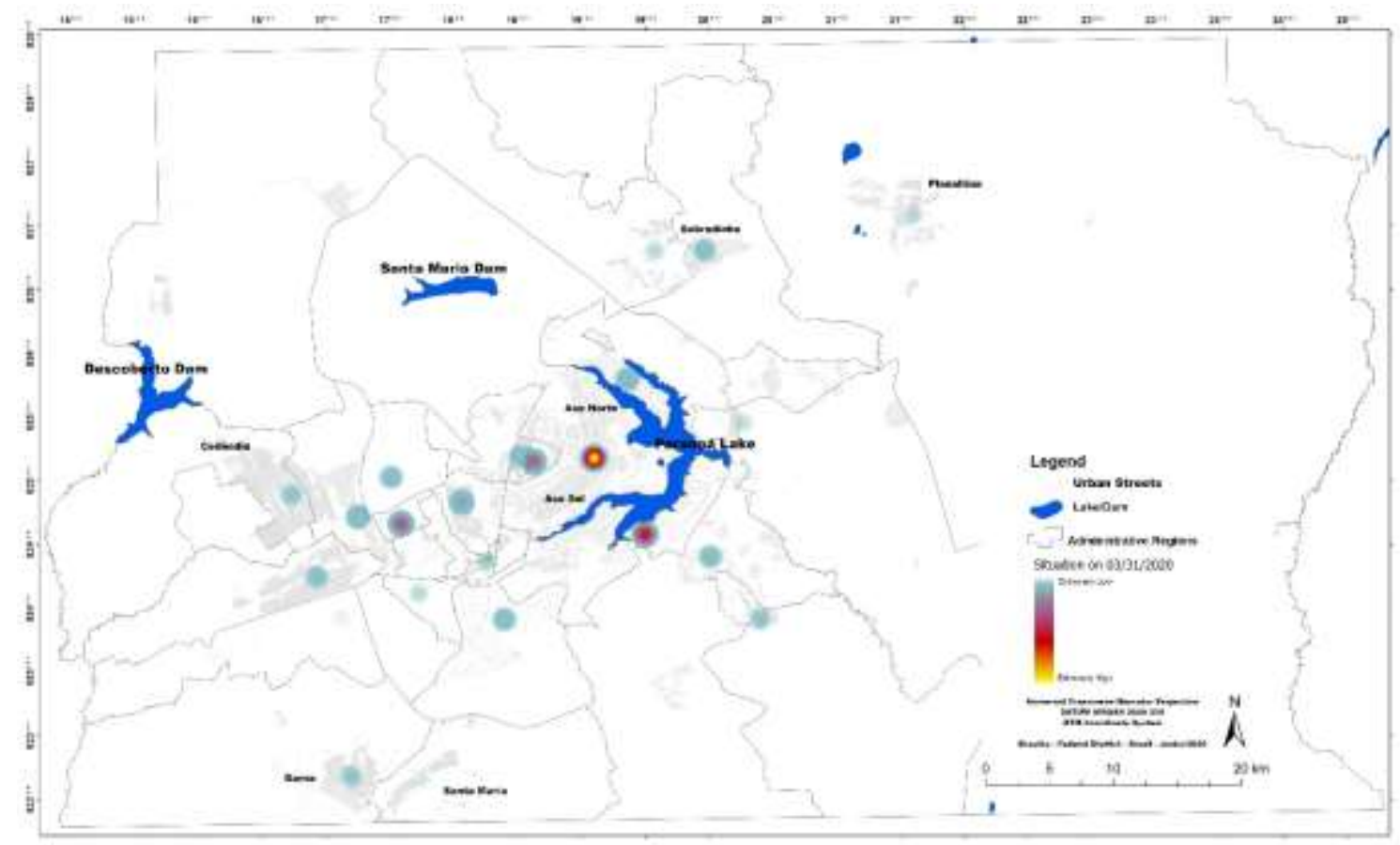

Figure 16. Spatial distribution of confirmed cases until 03-31-2020

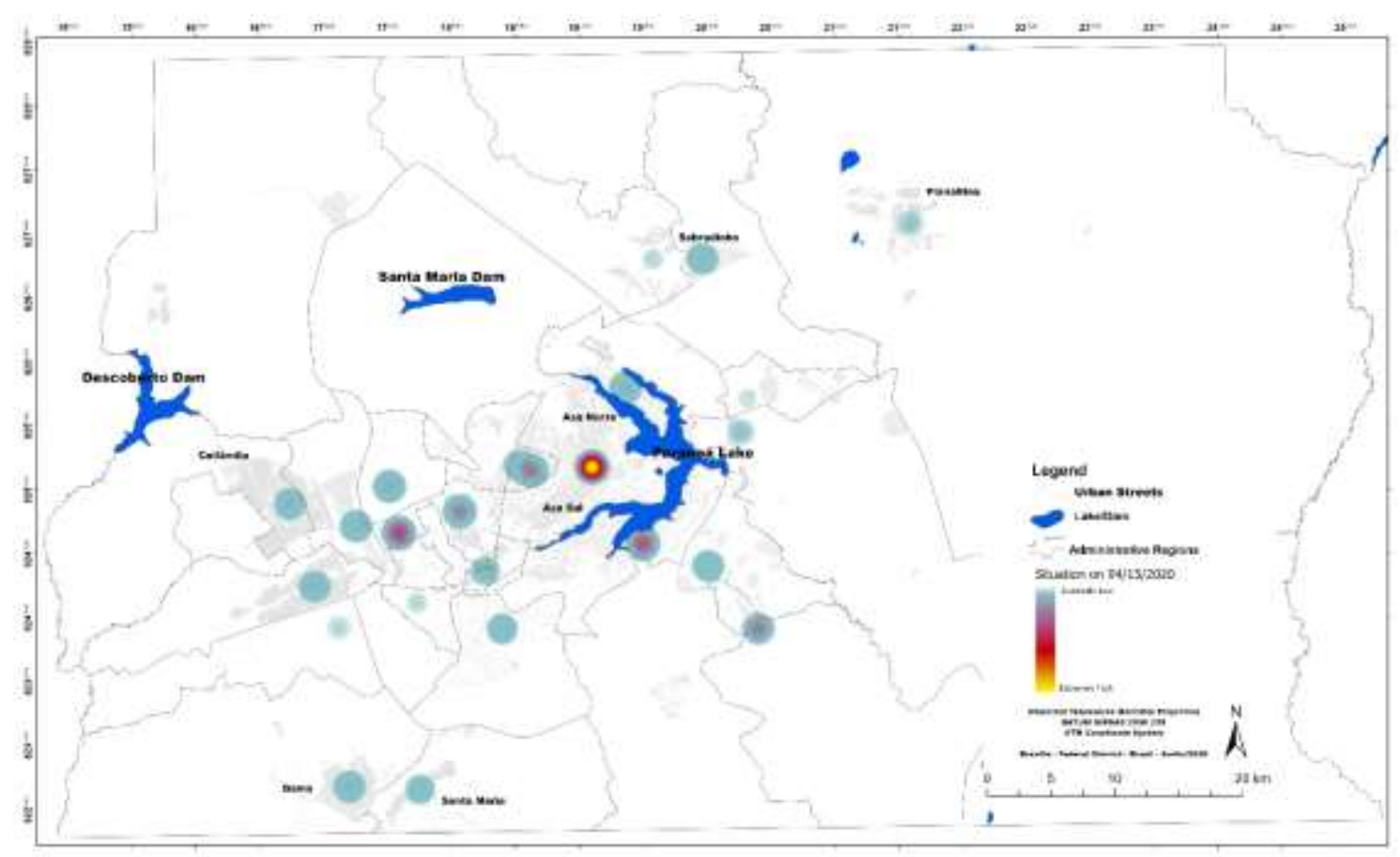

Figure 17. Spatial distribution of confirmed cases until 04-15-2020 


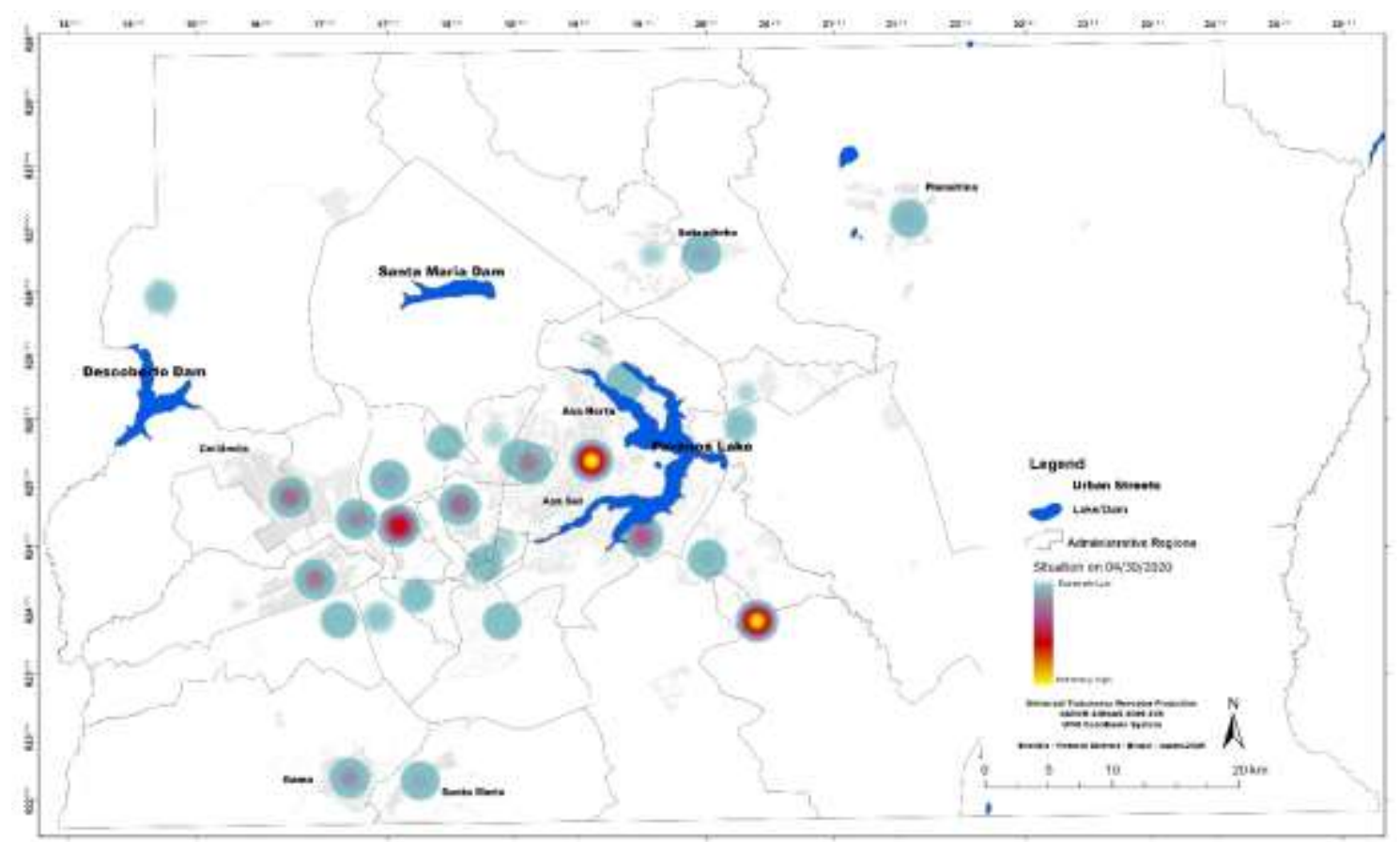

Figure 18. Spatial distribution of confirmed cases until 04-30-2020

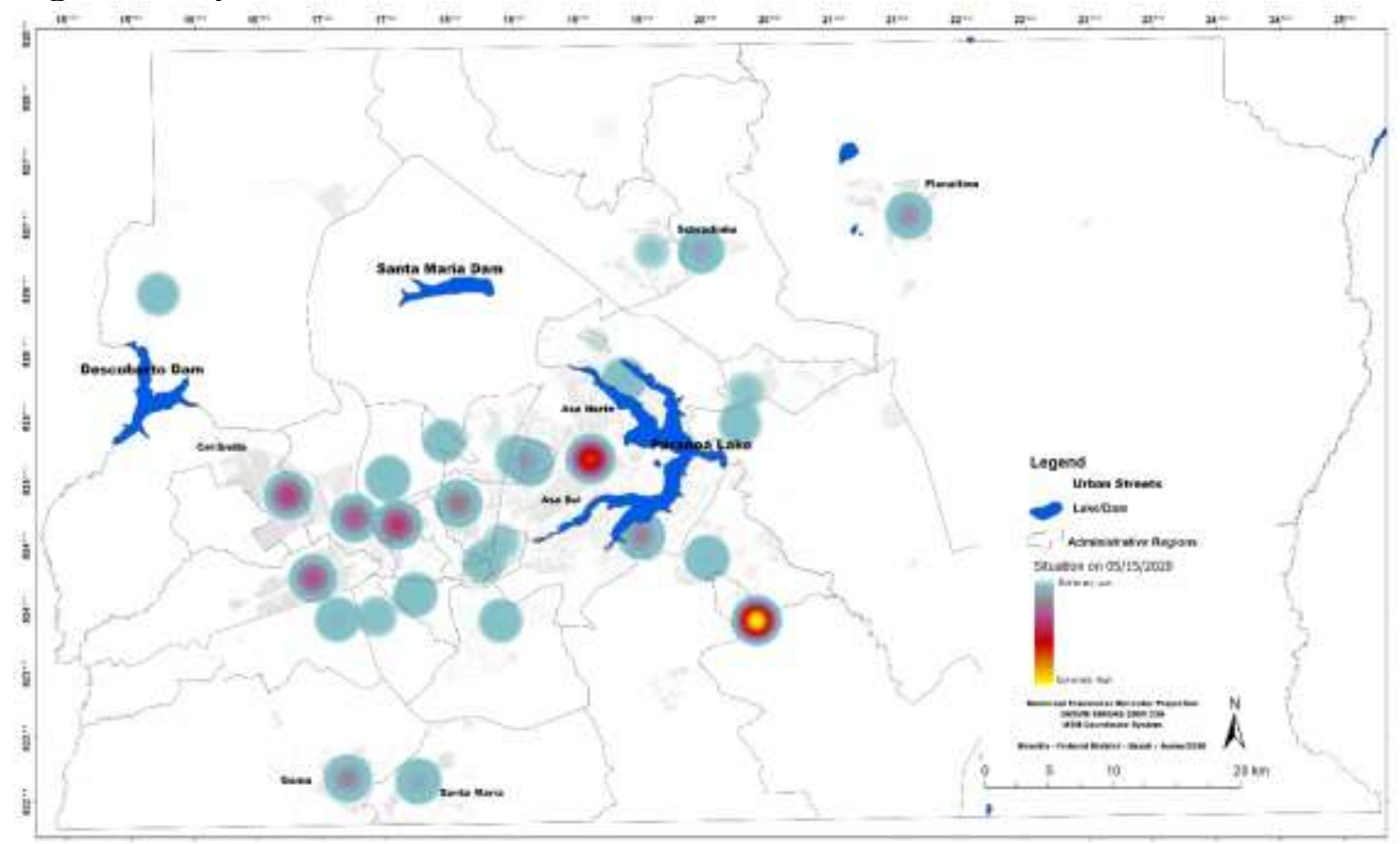

Figure 19. Spatial distribution of confirmed cases until 05-15-2020 


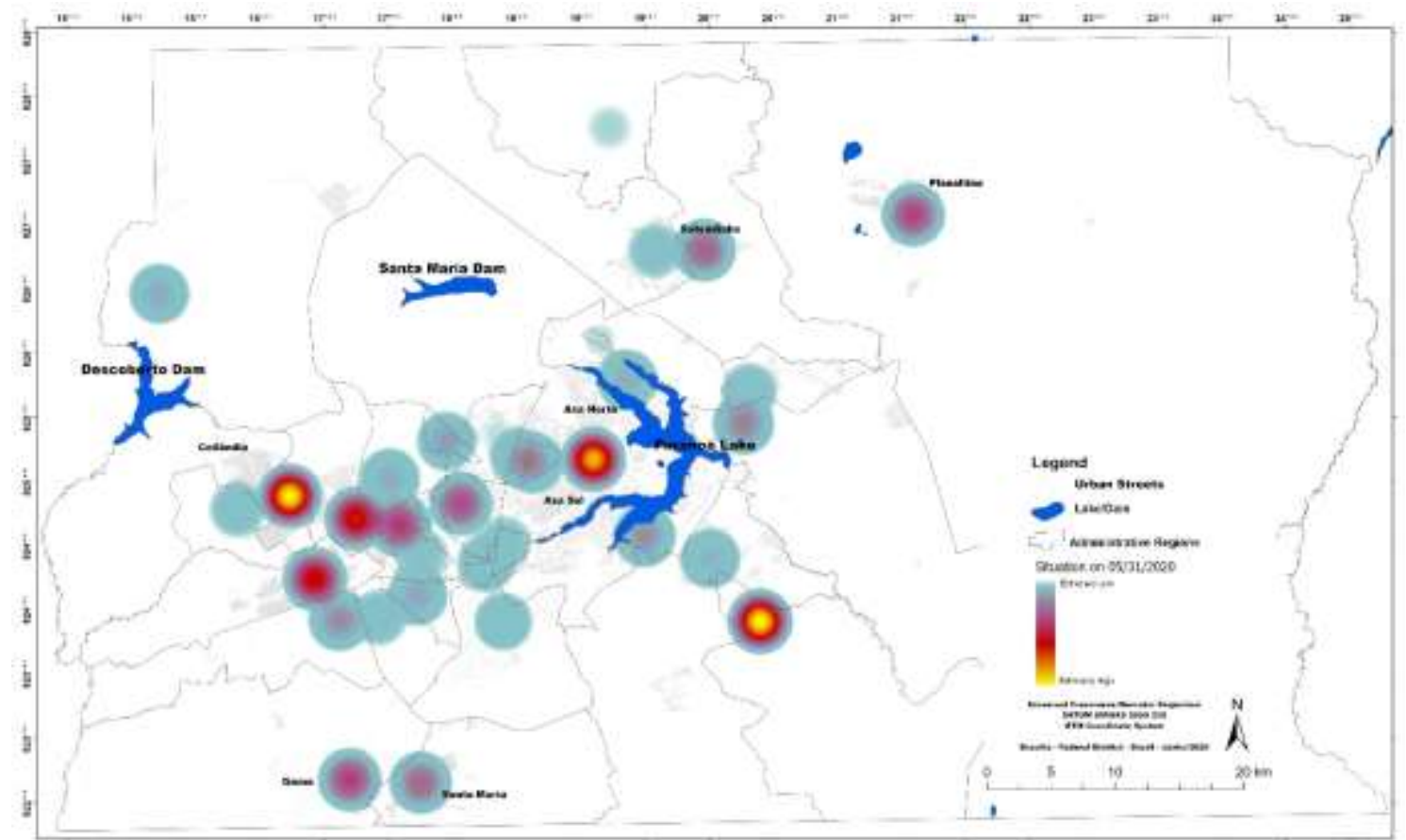

Figure 20. Spatial distribution of confirmed cases until 05-31-2020

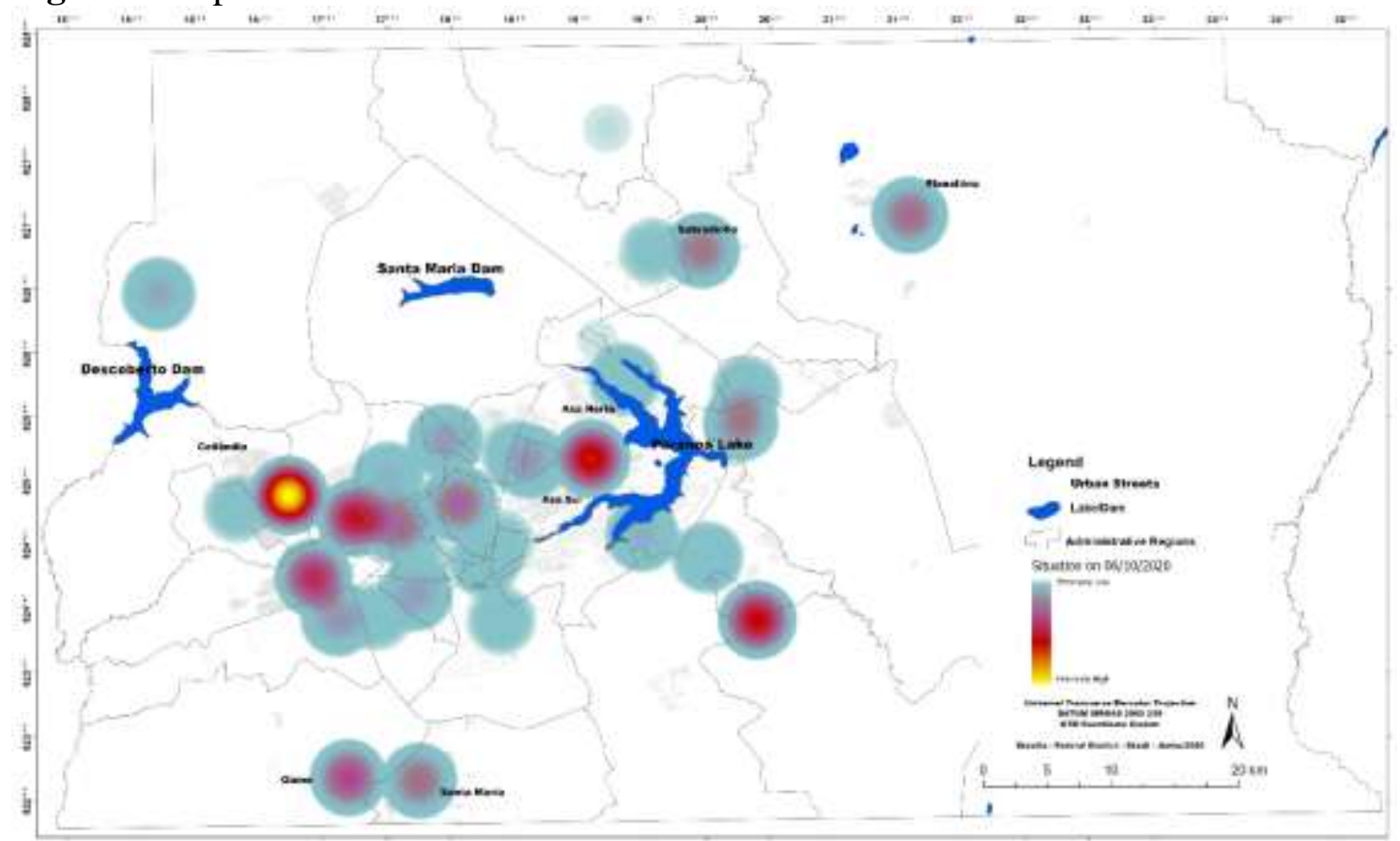

Figure 21. Spatial distribution of confirmed cases until 06-10-2020

These maps of daily evolution present the vector of the spread of the virus contagion, which had its growth towards the census sectors of vulnerability classified as extremely high.

The largest urban spot, located in the west of Brasília, has the biggest growth of contagion. Such dissemination is associated with high rates of commuting by workers, low rates of social isolation in peripheral regions, and other vulnerability factors already indicated by the proposed model. It is important to highlight that a high number of cases have been confirmed so far in the prison system, which is located geographically in the opposite direction to the general expansion of cases. 
To conclude the analysis of the results, the regions of greatest vulnerability appear prominently in the daily data curve for each administrative region. We selected five of the thirty-three administrative regions to set as an example, so it could be understood how relevant social indicators are in this type of pandemic (Figure 22).

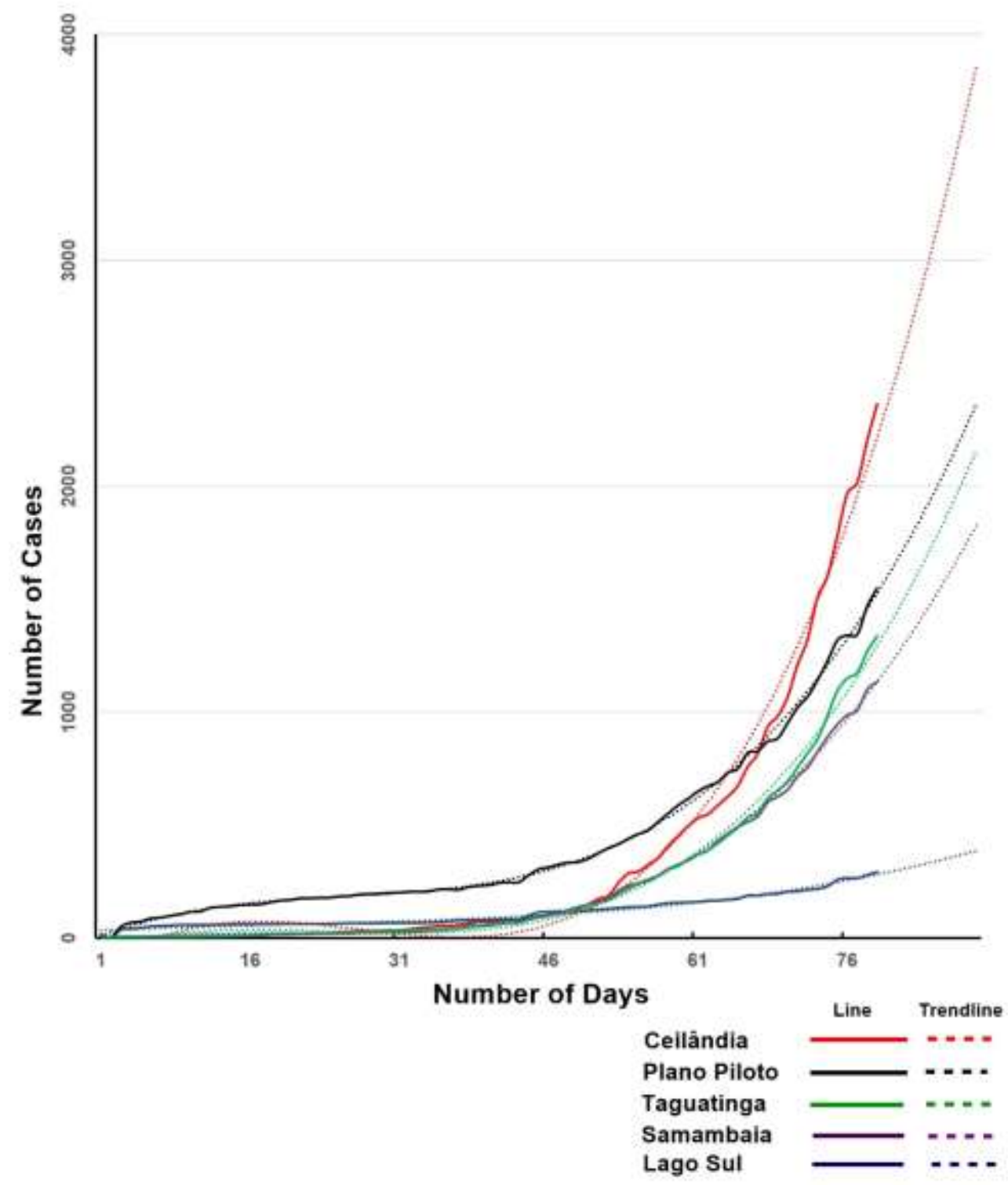

Figure 22: Daily evolution for confirmed COVID-19 cases in 5 ARs in the Federal District

In the presented graph, the two ARs that were the initial trigger of the cases, Plano Piloto and Lago Sul, and the three regions that have high levels of socio-spatial vulnerability were inserted. The daily growth curves show that these regions are still under a high contagion rate. The case of Ceilândia is the most worrying since it has a very sharp growing curve.

\section{Conclusions}

It is important to notice how the detail scale makes a difference when analyzing social-spatial data. In this case, it was used the census sector to obtain a bigger picture of what is happening and where is located the most vulnerable people in Brasília. 
Therefore, this kind of spatial analysis can be a helpful tool for researchers all over the globe that want to understand the socio-spatial vulnerability to restrain health disparities.

In Brazil, there is an incredible lack of information and data about its people. A lot of available data is outdated, and it is not much reliable. There is little information about public health, Family Health, and pre-existing conditions. The temporal oversight of the data is a serious problem because the demographic census is provided every ten years when it could be provided every five years or even less. In this study, we used the most recent studies made available by the government.

In the capital of Brazil, the complex services are concentrated in a few health units. In the case of COVID-19, the hospital of reference for the treatment has not the full capacity to include the demand of three million people who live in Brasília. Due to the results of the research, Brasília can face serious consequences if there is no respect for the mitigation and suppression measures.

Declarations

Ethics approval and consent to participate

Not applicable.

Consent for publication

Not applicable.

Availability of data and materials

The data that support the findings of this study are available from the Brazilian Institute of Geography and Statistics web site.

Competing interests

Funding

Not applicable.

Not applicable.

- Authors' contributions

GEP was a major contributor in writing the research, analyzed and interpreted the maps generated by VAS utilizing publicly available data. All authors have read and approved the final manuscript.

- Acknowledgments

Not applicable.

\section{References}

[1] Wuhan Municipal Health Commission. Report of clustering pneumonia of unknown etiology in Wuhan City. Wuhan, China: Wuhan Municipal Health Commission; 2019; 1. (http://wjw.wuhan.gov.cn/front/web/showDetail/2019123108989)

[2] Zhu, N, Zhang, D, Wang, W, et al. A Novel Coronavirus from Patients with Pneumonia in China, 2019. N Engl J Med. 2020;383(8):727-733. doi:

10.1056/NEJMoa2001017

[3] Paules, CI, Marston, HD, Fauci AS. Coronavirus infections - more than just the common cold. JAMA. 2020;323(8):707-708. doi:10.1001/jama.2020.0757

[4] de Wit, E, van Doremalen, N, Falzarano, D, Munster, VJ. SARS and MERS: recent insights into emerging coronaviruses. Nat Rev Microbio. 2016;14(8), 523-534.

doi:10.1038/nrmicro.2016.81

[5] WHO Coronavirus Disease (COVID-19) Dashboard. World Health Organization. (https://who.sprinklr.com/). Updated August 10, 2020, 3:06 pm CEST. Accessed August 10, 2020. 
[6] Huang, C, Wang, Y, Li, X, et al. Clinical features of patients infected with 2019 novel coronavirus in Wuhan, China. Lancet. 2020;395(10223):497-506.

doi:10.1016/s0140-6736(20)30183-5

[7] Ting, DSW, Carin, L, Dzau, V, Wong, TY. Digital technology and COVID-19. Nat Med. 2020;26(4):459-261. doi:10.1038/s41591-020-0824-5

[8] Allen, TR, Wong, DW. Exploring GIS, spatial statistics and remote sensing for risk assessment of vector-borne diseases: a West Nile virus example. Int J Risk Assess Manag. 2006;6(4/5/6):253-275. doi:10.1504/ijram.2006.009546

[9] Caprarelli, G, Fletcher, S. A brief review of spatial analysis concepts and tools used for mapping, containment and risk modelling of infectious diseases and other illnesses. Parasitology. 2013;141(5):581-601. doi:10.1017/s0031182013001972

[10] Braveman, P. Health Disparities and Health Equity: Concepts and Measurement. Annu Rev Publ Health. 2006;27(1):167-194. 2006; doi:

10.1146/annurev.publhealth.27.021405.102103

[11] Wang, Z, Tang, K. Combating COVID-19: health equity matters. Nat Med. 2020;26(4):458. doi:10.1038/s41591-020-0823-6

[12] Ferguson, NM, Laydon, D, Nedjati-Gilani, G, et al. Impact of non-pharmaceutical interventions (NPIs) to reduce COVID-19 mortality and healthcare demand.

https://spiral.imperial.ac.uk:8443/handle/10044/1/77482. Published March 16, 2020.

Accessed June 16, 2020.

[13] Secretary of Health of the Federal District. Boletins Informativos DIVEP/CIEVES (COE). Brasília: Brazil; Published June 14, 2020:1-7.

[14] Consulta leitos. DATASUS.

(http://cnes2.datasus.gov.br/Mod_Ind_Tipo_Leito.asp?VEstado=53). Updated 2020.

Accessed April 23, 2020.

[15] Kritski, A, Alves, D, Werneck, et al. Panorama da COVID-19.

https://ufrj.br/sites/default/files/img-noticia/2020/03/notatecnica25032020.pdf.

Published March 25, 2020. Accessed June 14, 2020.

[16] Movimento Nossa Brasília, Instituto de Estudos Socioeconômicos, Oxfam Brasil. Mapa das Desigualdades 2019. http://www.movimentonossabrasilia.org.br/mapa-dasdesigualdades/. Published 2019. Accessed June 14, 2020.

[17] Almeida E. Econometria espacial aplicada. Alínea; 2012.

[18] Anselin L. The local indicators of spatial association - LISA. Geogr Anal. 1995;27(2):93-115. doi: http://dx.doi.org/10.1111/j.1538-4632.1995.tb00338.x.

[19] Callaghan M, Cormican M, Prendergast M, et al. Temporal and spatial distribution of human cryptosporidiosis in the west of Ireland 2004-2007. Int J Health Geogr. 2009;8(64):1-9. doi: http://dx.doi.org/10.1186/1476-072X-8-64.

[20] Erdogan S. Explorative spatial analysis of traffic accident statistics and road mortality among the provinces of Turkey. J Safety Res. 2009;40(5):341-351. doi: http://dx.doi.org/10.1016/j.jsr.2009.07.006.

[21] Gómez-Barroso D, Nogareda F, Cano R, Pina MF, Del Barrio JL, Simon F. Spatial pattern of legionellosis in Spain 2003-2007. Gac Sanit. 2011;25(4):290-295. doi:

10.1016/j.gaceta.2011.02.011 